\title{
PADRÕES ESPACIAIS DAS TENDÊNCIAS DAS PRECIPITAÇÕES SAZONAIS E MENSAIS NO ESTADO DO PARANÁ - BRASIL
}

\author{
ELY, Deise Fabiana - deise.ely@gmail.com \\ Universidade Estadual de Londrina / UEL
}

\begin{abstract}
RESUMO: Com o objetivo de aprofundar a análise climática em escala regional, o presente artigo objetiva estudar a distribuição espaço-temporal dos totais pluviométricos sazonais e mensais no estado do Paraná e de suas tendências utilizando uma modelagem geoestatística que procura identificar as tendências por meio dos testes da Correlação Linear, de Mann-Kendall e dos mínimos quadrados ordinários; calculadas ao nível dos pixels dos mapas, com uma resolução espacial de um quilômetro. As chuvas anuais foram analisadas por meio do método gráfico cronológico de processamento da informação e foi estabelecida uma relação com os índices climáticos da Oscilação Sul e da temperatura da superfície do mar na região do El Niño 3.4; sendo constatado que as médias das precipitações anuais estão em fase com tais índices. Foi verificado que as chuvas sazonais e mensais no Paraná apresentam a variabilidade característica deste fenômeno meteorológico, mas com áreas em que os valores são mais significativos para o aumento do que para a redução. As tendências positivas identificadas para as estações de verão, inverno e primavera são influenciadas pelos valores também positivos dos meses de janeiro, fevereiro, junho, julho e outubro.
\end{abstract}

PALAVRAS-CHAVES: modelagem geoestatística; análise climática regional; tendências espaço-temporais

\section{SPATIAL PATTERNS OF SAZONAL AND MONTHLY PRECIPITATION TRENDS IN PARANÁ - BRAZIL}

ABSTRACT: Intending to deepen the climatic analysis on a regional scale, this paper studies the spatial-temporal distribution of seasonal and monthly rainfall totals in Paraná, and its trends, through the geostatistical modeling carried out by Ely and Dubreuil (2017) to identify spatial-temporal, through the Mann- Kendall and OLS Linear Correlation tests. The distribution was calculated at the map pixel level, with a spatial resolution of one kilometer. Annual rainfall was analyzed using the MGCTI methodology (NOUACEUR; LAIGNEL; TURKI, 2014) and a relationship was established with the SOI and SST index. It was observed that the means of the annual precipitations are according to such index. It was verified that the seasonal and monthly rains in Paraná present the characteristic variability of this meteorological phenomenon, but with areas where the values are more significant for the increase than for the reduction. The positive trends identified for the summer, winter and spring seasons are influenced by the positive values of January, February, June, July and October.

KEYWORDS: geostatistical modeling; regional climate analysis; spatiotemporal trends

CONFIGURATIONS SPATIALES DES TENDANCES SAISONNIÈRRES ET MENSUELLES DANS L'ÉTAT DU PARANÁ - BRÉSIL

RÉSUMÉ: Afin d'approfondir l'analyse du climat à l'échelle régionale, cet article propose d'étudier la répartition spatiale et temporelle des totaux pluviométriques saisonniers et mensuels dans l'État du Paraná et leurs tendances à l'aide d'une approche de modélisation géostatistique qui permet d'identifier l'origine spatiale à l'aide des tests de corrélation linéaire, de Mann-Kendall et de le moindres carrés ordinaires. Ces divers tests ont été calculés au niveau des pixels de la carte, avec une résolution spatiale d'un kilomètre. Les précipitations annuelles ont été analysées à l'aide de la méthode graphique chronologique de traitement de l'information et une relation a été établie avec les indices climatiques d'oscillation australe et de la température de surface de la mer. Nous avons vérifié si les pluies saisonnières et mensuelles au Paraná présentaient une variabilité pouvant être expliquée par ces phénomènes météorologiques. Les zones où les 
valeurs sont les plus significatives correspondent à celles où il y a eu une augmentation plutôt qu'une réduction. Les tendances positives identifiées pour les saisons d'été, d'hiver et de printemps sont influencées par les valeurs positives des mois de janvier, février, juin, juillet et octobre.

PALABRAS CLAVE: modélisation géostatistique; analyse du climat régional; tendances spatio-temporelles.

\section{INTRODUÇÃO}

O estado do Paraná, localizado no sul do Brasil, tem enfrentado os impactos decorrentes de fenômenos climáticos extremos, tais como precipitações intensas, inundações, secas e ondas de calor, dentre outros. Assim como em outros estados brasileiros, a população paranaense está concentrada em áreas urbanas que dependem da produção de energia hidrelétrica para o desenvolvimento das atividades cotidianas e industriais (o estado conta com mais de vinte usinas em seu território) e, para a regularidade da produção de energia, necessita da manutenção dos níveis dos reservatórios. Bem como sua economia, fortemente dependente das atividades agrícolas e, também, vulneráveis à variabilidade do clima.

Dubreuil et al (2012) esclarecem que a variabilidade de um dado parâmetro climático pode se dar mais ou menos em torno de um valor de referência central (da normal climatológica, por exemplo), ou seja, por meio de sua análise é possível observar os anos mais ou menos quentes ou mais úmidos e secos. E destacam que o desenvolvimento técnico das sociedades permitiu sua adaptação a estes referenciais climáticos. Os autores se referem à variação climática como uma alteração progressiva e duradoura no clima, tornando-se década após década mais frio ou mais quente. Esta não é a observação de um ou dois anos, mesmo se ela for consecutiva e, para afirmar a ocorrência desse tipo de tendência são necessárias observações durante um longo período de tempo, da ordem de meio século.

De acordo com Nascimento Júnior, Silvestre, Dubreuil e Sant'Anna Neto (2013) a análise e a descrição dos fenômenos meteorológico-climáticos é efetuada por meio de dados numéricos, que prescinde da utilização de técnicas estatísticas (distribuição de frequência, medidas de tendência central, de dispersão, de variabilidade, correlações, dentre outras), representações gráficas e a construção de modelos que representem sua repercussão no território. Os autores ainda destacam que "O intuito da utilização dessas técnicas é a definição de (des)continuidades, (a)ritmias, variações de máximas e mínimas, que podem ocorrer de forma sequencial ou não, e/ou com ausência/presença de padrão específico, inerente à ideia e ao conceito de variabilidade climática" (2013, p. 2).

Os relatórios produzidos pelo Painel Intergovernamental de Mudanças Climáticas (IPCC - sigla em inglês) têm enfatizado que nas regiões continentais o número de episódios de precipitações extremas mais aumentou que diminuiu, que os eventos extremos de precipitação estão se tornando mais frequentes e intensos na maior parte das áreas localizadas nas latitudes médias continentais e nos trópicos úmidos; mas que em muitas áreas das latitudes médias e nas regiões subtropicais secas a precipitação média irá diminuir. 
Enquanto que a variabilidade e os extremos climáticos na América do Sul e no Brasil têm sido abordados por uma série de estudos (principalmente sobre as variáveis das temperaturas e / ou precipitações: Haylock et al, 2006; Marengo et al, 2009; Almeida et al, 2016; Oliveira et al, 2016; Otto et al, 2015, dentre outros) mas, também, é ressaltado que a atribuição desses extremos não é claramente abordada na escala regional. Marengo et al (2009) enfatizam que os modelos globais têm permitido uma melhor compreensão científica das mudanças climáticas na escala global, mas que a escala regional necessita de projeções que sejam mais relevantes pois a adaptação da sociedade, em oposição à mitigação, é inerente às escalas local e regional. Estas escalas demandam por uma investigação mais aprofundada que possa viabilizar o desenvolvimento de estratégias adequadas à adaptação, principalmente sobre o conjunto de impactos na agricultura, no gerenciamento de recursos hídricos, saúde, entre outros. E ainda destacam que as projeções regionais de mudança climática constituem o principal fator para subsidiar sistemas de decisão que visam à redução da vulnerabilidade.

Com o intuito de produzir uma análise regional e identificar as tendências espaço-temporais das chuvas, Ely e Dubreuil (2017) elaboraram uma modelagem geoestatística dos totais pluviométricos anuais do período de 1977 a 2014 para o estado do Paraná. E constataram que as tendências estatisticamente significativas são aquelas que indicam aumento nos totais pluviométricos anuais, principalmente nas mesorregiões: metropolitana (mais especificamente Curitiba e o norte do litoral paranaense), centro-sul, oeste (Catanduvas), centro-ocidental (Altamira do Paraná), norte central e norte pioneiro.

Ely e Fortin (2018) procuraram refinar a análise das tendências das precipitações em duas regiões do Paraná (norte e leste) e produziram um estudo considerando seis índices (ETCCDMI / Painel Intergovernamental sobre Mudanças Climáticas - IPCC) calculados para a série pluviométrica diária para o período de 1971 a 2014. E identificaram que ocorrem aumentos significativos nos totais anuais (PRCPTOT) das estações meteorológicas da Lapa, Curitiba e Guaraqueçaba. Estas duas primeiras estações também registraram aumentos significativos nos dias consecutivos com precipitações superiores a $30 \mathrm{~mm}$ (Rxnday). Todas as estações localizadas no leste do estado apresentaram tendência significativa de aumento do número de dias chuvosos acima de $20 \mathrm{~mm}$ (R20mm); enquanto as estações localizadas ao norte indicaram redução dos índices de precipitação, mas esta redução não é estatisticamente significativa.

Em uma análise que procurou identificar mudanças nas precipitações na bacia hidrográfica do rio Paraná, Zandonadi et al (2016) assinalam um aumento na precipitação total no sul da bacia, ou seja, no estado do Paraná, principalmente com aumentos nas chuvas superiores a 10 e $20 \mathrm{~mm}$ diários.

Aquino (2012, p. 96) destaca os cenários previstos pelo Painel Brasileiro de Mudanças Climáticas (PBMC) para o bioma da Mata Atlântica, localizado nos estados do Paraná e Santa Catarina, que projetam uma intensificação das chuvas entre 5 e $10 \%$ até o ano de 2040 ; de 15 a $20 \%$ no período de 20412070 e de 25 a $30 \%$ no final do século XXI (2071-2100).

Com o objetivo de aprofundar o estudo da variabilidade da precipitação em escala regional, o presente artigo analisa a distribuição espaço-temporal dos totais pluviométricos sazonais e mensais no estado do Paraná e de suas 
tendências por meio da modelagem geoestatística realizada por Ely e Dubreuil (2017).

\section{METODOLOGIA}

O desenvolvimento do presente trabalho partiu da sistematização das planilhas anuais, mensais e sazonais dos dados pluviométricos diários oriundos de 605 estações e postos pluviométricos das redes de coleta do Instituto Agronômico do Paraná (IAPAR), do Instituto Nacional de Meteorologia (INMET) e da Agência Nacional de Águas (ANA) para o período de 1977 a 2016 que, em conjunto, propiciam uma maior densidade espacial de dados; requisito para a aplicação da referida modelagem.

Mas, devido às falhas nas séries e tendo como critério a manutenção das estações e postos que tivessem até $10 \%$ de dados faltantes na análise para que se pudesse ter uma maior abrangência espacial dos mesmos, foram manipulados os dados pluviométricos de 330 postos e estações (figura 1), sendo 323 localizados no Paraná e 7 nos limites dos estados de São Paulo, Santa Catarina e Mato Grosso do Sul.

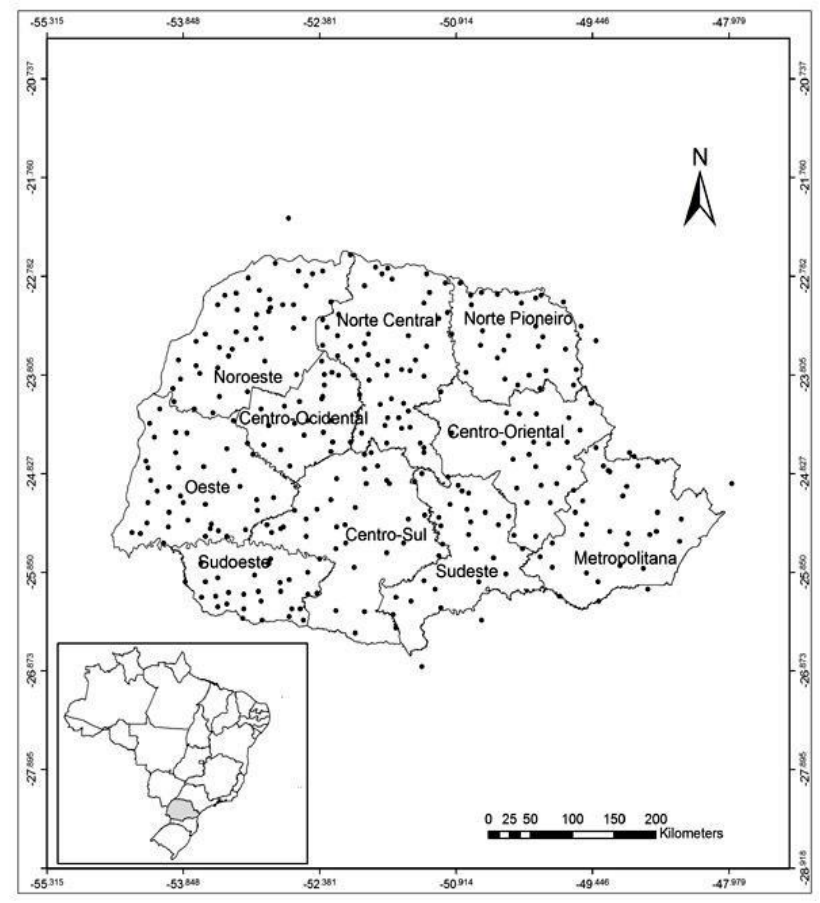

Figura 1 - Localização dos postos / estações. (elaborado pela própria autora)

Com o objetivo de obter uma análise regional dos dados anuais, primeiramente, foi aplicado o método gráfico cronológico de tratamento da informação (MGCTI) do tipo Matriz de Bertin (NOUACEUR; LAIGNEL e TURKI, 2014) que se dá por meio de duas etapas:

1) os dados pluviométricos anuais são organizados em ordem crescente. Posterioremente cada ano é classificado de acordo com valores-limites definidos 
por meio do método dos quantis que, de acordo com S. Xavier, Xavier e Alves (2007), permitem identificar ou separar não apenas observações numéricas pertencentes as categorias extremas; mas ainda, aquelas posicionadas em categorias intermediárias (uma classe centralizada compreendendo, em princípio, a mediana ou a média). Desta forma foram estabelecidos os intervalos quantílicos Q1 - extremamente secos, Q2 - secos, Mediana, Q3 - úmidos e Q4 extremamente úmidos para todos os postos e estações e para todos os anos da série;

2) substituição dos totais pluviométricos anuais dos intervalos quantílicos por uma legenda de cores que compõe um quadro com as precipitações pluviométricas anuais de cada estação e posto pluviométrico. Em seguida foi feito um reordenamento das colunas partindo dos postos mais secos para os mais úmidos, seguindo o princípio da matriz de Bertin (NOUACEUR; LAIGNEL e TURKI, 2014). E, para determinar os diferentes períodos da variabilidade das precipitações anuais, foram atribuídos os números de 1 (ano extremamente seco) a 5 (ano extremamente úmido) para cada quadrícula colorida que compõe o quadro. O total da soma dos números atribuídos para cada ano de cada estação, posteriormente, foi submetido à estatística da padronização e, assim, obteve-se um índice que varia de $+2,0$ a $-2,0$. O resultado é apresentado na figura 2 e possibilita analisar a variabilidade das chuvas anuais em uma escala regional e visualizar diferentes períodos (secos ou úmidos).

Para a identificação dos padrões espaciais das tendências das precipitações sazonais e mensais no Paraná foi aplicada a metodologia detalhada por Ely e Dubreuil (2017) com a elaboração da modelagem por meio do módulo Earth Trends Modeler (ETM - disponível no software IDRISI@ 19872012 Clark University, versão Selva 17.00), que permite a produção de uma sequência temporal de imagens e possibilita a análise de tendências de longo prazo com sete opções de saída.

No presente estudo são analisados os resultados de três testes resultantes da referida modelagem (correlação linear - R2, tendência monotônica de Mann-Kendall e tendência linear OLS), que apresentaram desempenhos mais significativos e que têm sido frequentemente empregados na caracterização de tendências de diferentes parâmetros climáticos (DEBORTOLI; DUBREUIL; HENKE e RODRIGUES FILHO, 2012; TOZATO; DUBREUIL e DE MELLO-THÉRY, 2014; NASCIMENTO JÚNIOR; SILVESTRE; DUBREUIL $\mathrm{P}$ SANT'ANNA NETO, 2013; ELY e DUBREUIL, 2014 e 2017; CARMELLO; DUBREUIL e SANT'ANNA NETO, 2015).

O teste da correlação linear, conforme Back (2001), pode ser utilizado para indicar alterações climáticas por meio do teste de significância do coeficiente angular, que consiste em determinar o intervalo de confiança do coeficiente "a". O procedimento do cálculo da correlação linear identifica o coeficiente de determinação (R2) a partir de uma regressão linear entre os valores de cada pixel ao longo do tempo para uma determinada série linear. No IDRISIC este cálculo considera a correlação linear de Pearson entre os valores de cada pixel ao longo da série histórica espacialmente distribuída.

O teste de Mann-Kendall é um teste não paramétrico utilizado para identificar mudanças climáticas em séries temporais de dados que, na hipótese da estabilidade de uma série temporal, os valores devem ser independentes e a distribuição de probabilidades deve permanecer sempre a mesma (série 
aleatória simples). Na aplicação do teste estatístico da tendência monotônica de Mann-Kendall a série de dados é a variável dependente e o tempo é a variável independente. Por meio da qual é possível verificar se as duas variáveis estão ambas aumentando ou diminuindo (conhecida como uma concordância) ou se uma aumenta enquanto a outra diminui (uma discordância) entre todas as combinações de pares de observações. Tau ( $\mathrm{T}$ ) é, então, a frequência relativa de concordâncias menos a frequência relativa de discordâncias. (HAYLOCK et al, 2006)

No referido módulo do IDRISI C foi aplicado o teste de Mann-Kendall para detectar tendências monotônicas, que fornece um indicador de tendência não linear que mede o grau em que a tendência é consistentemente crescente ou decrescente e varia no intervalo de -1 a 1 . Um valor 1 indica uma tendência que aumenta continuamente e nunca diminui. O inverso é verdadeiro, quando se tem um valor de -1 . Um valor 0 indica que não há tendência consistente (HAYLOCK et al, 2006). Todas as combinações de pares de valores ao longo do tempo são avaliadas para cada pixel e uma contagem é feita para verificar se o número tende a aumentar ou a diminuir com o tempo. (SALVIANO; GROPPO e PELEGRINO, 2016)

O teste de Mann-Kendall usado para detectar tendências monotônicas (de aumento ou diminuição) é amplamente utilizado para detectar tendências em séries temporais porque é simples, robusto, se adapta aos dados faltantes e os dados não precisam estar em conformidade com qualquer distribuição estatística. Em havendo chances de inconstâncias na série de dados, o teste não paramétrico de Mann-Kendall é útil, pois sua estatística está baseada nos sinais (+ ou -), ao invés de valores de variável randômica e, por conseguinte, as tendências determinadas são menos afetadas pelas inconsistências. (CHAKRABORTY; PANDEY; CHAUBE e MISHRA, 2013)

A opção da regressão de tendência linear (OLS) mapeia o coeficiente de declividade dos ordinários mínimos quadrados de regressão entre os valores de cada pixel ao longo do tempo para uma série perfeitamente linear. O resultado é uma expressão da taxa de variação por intervalo de tempo. Assim, se seus dados são anuais, ela expressa a taxa de ganho anual. Se forem mensais, indica o ganho ou perda mensal.

Vale destacar que no presente estudo foram produzidas análises a partir do conjunto de dados pluviométricos da série histórica de 1977 a 2016 objetivando verificar a distribuição espaço-temporal das chuvas sazonais e mensais no estado do Paraná e de suas tendências espaciais por meio da modelagem descrita, ou seja, as tendências são calculadas ao nível dos pixels dos mapas e não a partir das séries pontuais; como é feito na maioria dos trabalhos.

\section{DISCUSSÃO DOS RESULTADOS}

Na figura 2 é possível visualizar a variabilidade espaço temporal das chuvas no Paraná e é verificada uma estrutura organizada em fases bem definidas: 1) uma seca entre 1977 a 1981 com índices padronizados inferiores a -1; 2) uma úmida entre 1982 e 1998 na qual os índices, em sua maioria, são positivos e em 6 anos superiores $a+1$; 3) uma fase seca entre 1999 e 2012, com predominância de índices negativos e para três anos (1999, 2006 e 2012) 
com valores negativos inferiores a -1 e 4) uma última fase que parece romper com a tendência decrescente das chuvas da fase anterior, pois todos os anos entre 2013 e 2016 apresentam índices positivos (2013 ultrapassa o valor +1, caracterizado por excendentes pluviométricos).

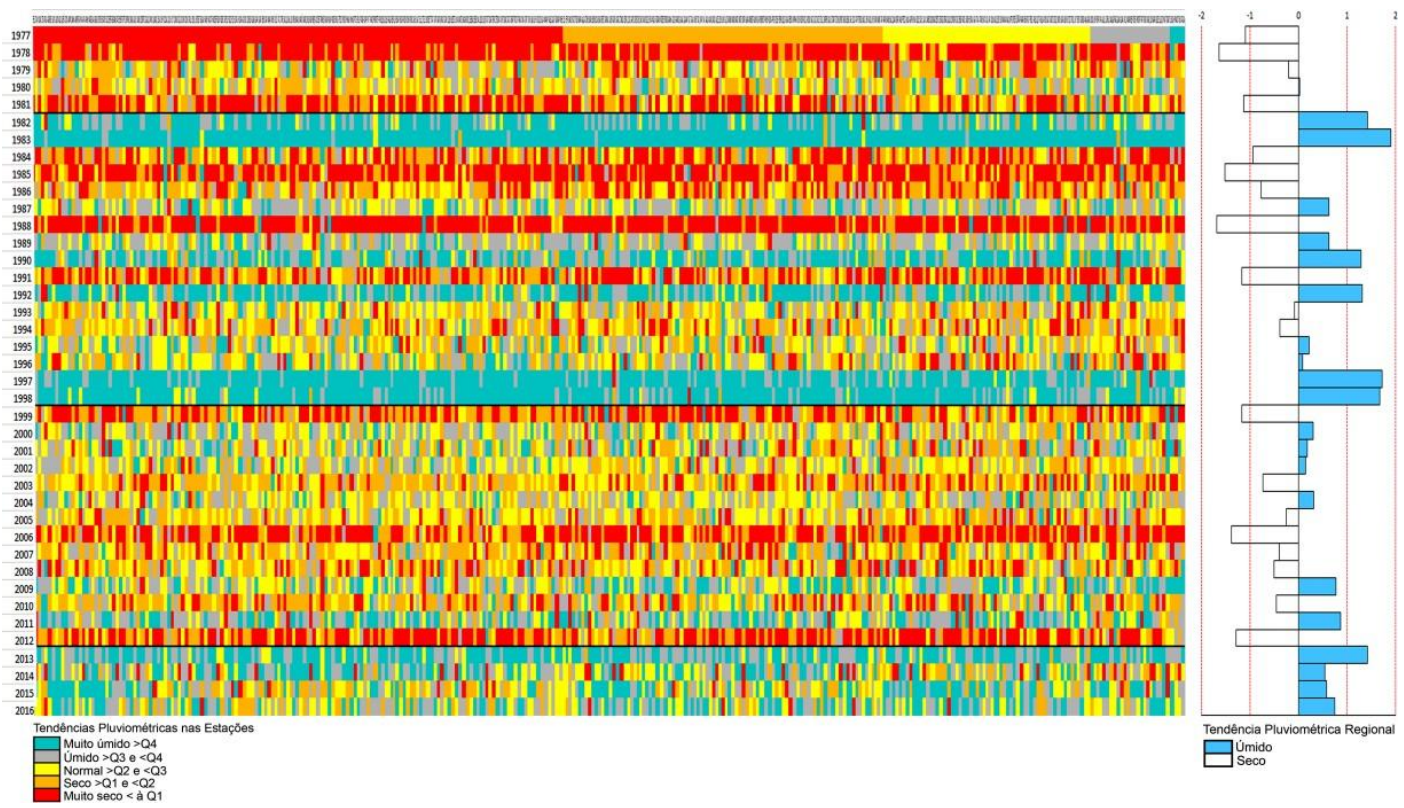

Figura 2 - Matriz MGCTI aplicada às precipitações totais anuais no estado do Paraná (1977 a 2016). (elaborado pela própria autora)

Frequentemente, as variáveis climáticas são analisadas de forma independente, embora, na realidade, estejam intimamente correlacionadas entre si e com a circulação geral da atmosfera (TRENBETH et al, 2015). Na presente análise, procurou-se estabelecer uma relação da variabilidade anual da precipitação com o Índice de Oscilação do Sul (SOI, sigla em inglês) e com a temperatura da superfície do mar (SST, em inglês sea surface temperature) na região do El Niño 3.4; reconhecidos por afetar o clima do sul do Brasil (MARENGO et al, 2009; GRIMM, 2009; SOUSA, 2006; PINHEIRO, 2016).

Liebmann et al (2004) também reforçam que ocorre uma intensificação dos efeitos do El Niño-Oscilação Sul (ENOS) no sul do Brasil quando se dá, simultaneamente, o aumento na temperatura da superfície do mar (SST) em parte do Oceano Atlântico Sul.

A análise das 4 fases identificadas na figura 2 demonstra uma relação convincente com o ENOS, pois em fase positiva de ENOS os anos mais úmidos são mais frequentes e em fase negativa de ENOS predominam os anos secos. Na figura 3 observa-se que as médias anuais das precipitações no Paraná estão em fase com os dois índices (a SST na região EI Niño 3.4 e a SOI), quando reduz a SST a SOI aumenta e a chuva diminui (1985, 1988, 1996, 1999, 2008, 2010). Mas a relação contrária nem sempre se concretiza. 


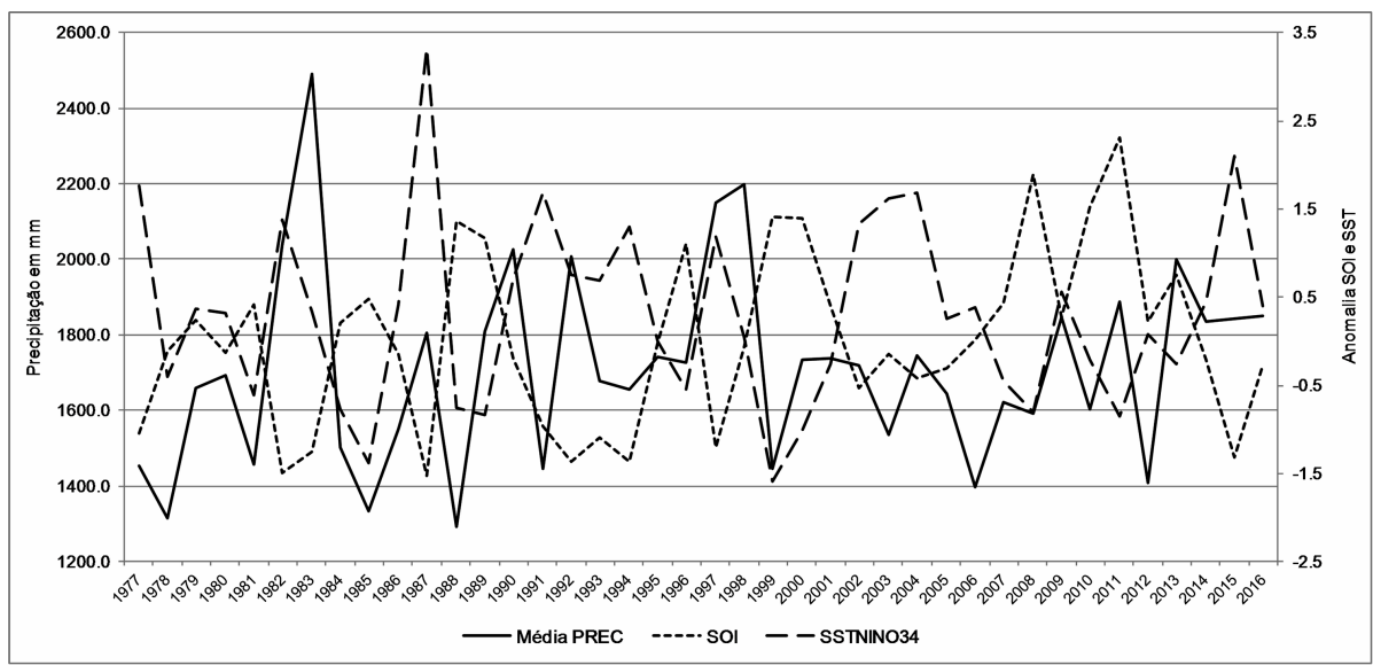

Figura 3 - Precipitação média anual no Paraná no período de 1977 a 2016, incluindo as médias das anomalias do índice de Oscilação Sul (SOI) e da Temperatura da superfície do mar (SST) na região do El Niño 3.4. (elaborado pela própria autora)

Na figura 4 observa-se que a média da precipitação anual no Paraná não apresenta uma tendência positiva acentuada, já que o valor crítico de referência de $r$ calculado para uma significância de $10 \%$ deve ser superior a 0,264; conforme Rogerson (2012). Assim, como ressaltam Barros, Doyle e Camilloni (2008), para o sul do Brasil ocorre uma mudança na média que, em virtude da disponibilidade dos dados somente após 1977, é mais visível depois de 1992.

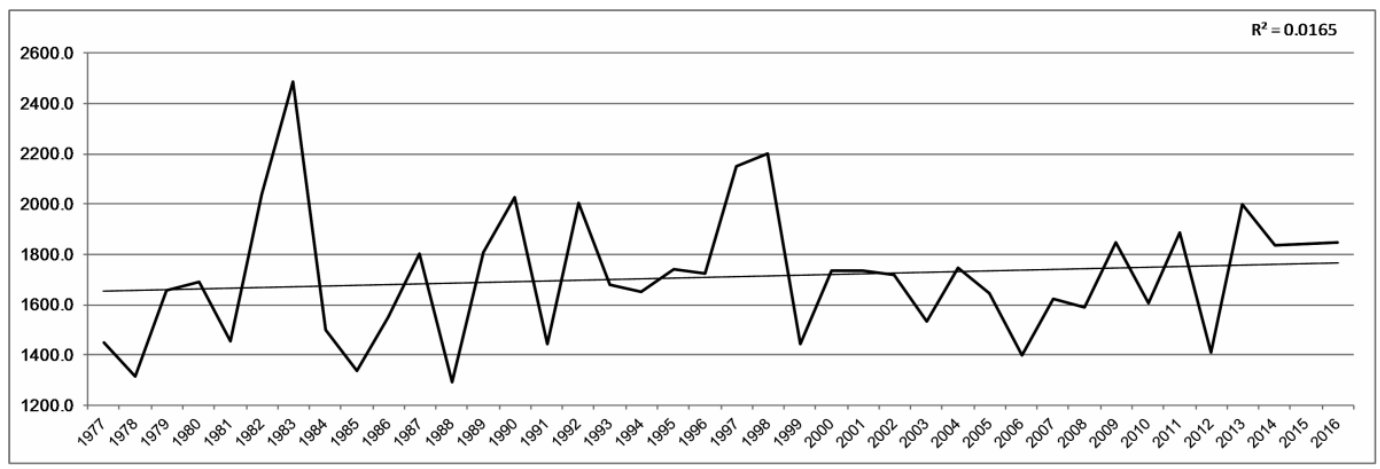

Figura 4 - Precipitação média anual no Paraná no período de 1977 a 2016.(elaborado pela própria autora)

Barros, Doyle e Camilloni (2008) enfatizam que os extremos de chuvas ligados aos eventos fortes de ENOS no sudeste da América do Sul no século XX podem estar relacionados à modulação deste fenômeno com a oscilação decadal do Pacífico (PDO, sigla em inglês); modo interdecadal que presenciou alterações no seu valor médio por volta de 1976 e que incluiu a mudança da SOI para valores predominantemente negativos. Nascimento Júnior (2013) identificou correlações significativas da variabilidade das precipitações no Paraná com a PDO no outono, na primavera e na escala anual; sendo que o número de dias com chuva apresentou correlações positivas somente para a primavera.

Ano 15 - Edição Especial - XIII Simpósio Brasileiro de Climatologia Geográfica - JUN 2019 
De acordo com a figura 5, as anomalias da PDO permaneceram positivas no período de 1977 a 1989, quando é verificada uma relação positiva deste índice climático com a média das precipitações apenas nos anos de 1983 e 1987. A partir de 1990 e 1991 a PDO registrou anomalias negativas e produziu um efeito atrasado na redução da média pluviométrica no ano de 1991 . De 1992 a 1999 verifica-se que a média pluviométrica no estado está em fase com a PDO.

O período de 1990 a 2012, identificado como seco na MCGTI (figura 2) não coincide com a variabilidade das anomalias da PDO. Apena o ano de 2012 demonstra um atraso na redução das chuvas, pois as anomalias negativas da PDO se instalaram um ano antes (2011).

De 2013 a 2016 os valores das anomalias da PDO saltam de -0,5 para 1,5 , coincidindo com a instalação de um período chuvoso no Paraná de acordo com a MGCTI (figura 2).

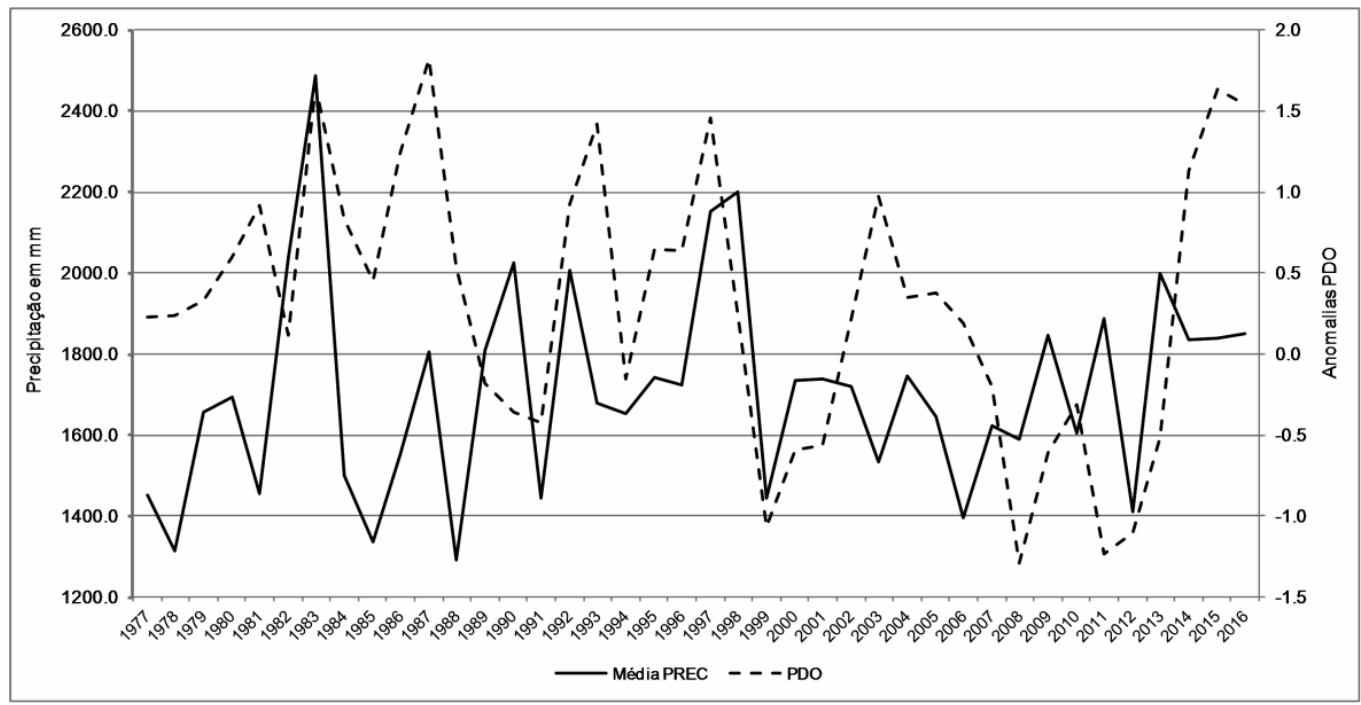

Figura 5 - Precipitação média anual no Paraná no período de 1977 a 2016 e anomalias da oscilação decadal do Pacífico (PDO, sigla em inglês). (elaborado pela própria autora)

Cavalcanti e Ambrizzi (2009) salientam que, além do ENOS, a oscilação do Pacífico América do Sul (PSA) exerce influência na atividade convectiva da zona de convergência do Atlântico Sul (ZCAS); enquanto o modo anular do hemisfério sul (SAM) influencia o deslocamento dos jatos subtropical e polar; alterando a trajetória dos ciclones extratropicais.

Silva (2001) procurou associar as variabilidades sazonais e interanuais das precipitações no sul do Brasil com as TSM's dos oceanos Pacífico Centroleste (PACE) e Atlântico Sudoeste (ATLSW) e demonstrou que ocorre um percentual maior de meses chuvosos quando são verificadas TSM's positivas no PACE e no ATLSW, mas que não há correlação significativa quando as TSM's são negativas nos dois oceanos. 
Aquino (2012) verificou que o SAM possui impacto importante sobre as temperaturas médias mensais (TMM) e sazonais do sul do Brasil e da península Antártica, com correlação negativa no outono, quando anomalias negativas (positivas) de TMM no sul do Brasil e positivas (negativas) na península Antártica estão associadas à fase positiva (negativa) do SAM.

Com relação à espacialização das médias pluviométricas no Paraná, observa-se que elas aumentam do norte $(1400 \mathrm{~mm})$ em direção ao sul (2000 a $2200 \mathrm{~mm}$ ), sendo que o litoral é a região mais chuvosa; onde as médias históricas são superiores a 2400mm (figura 6).

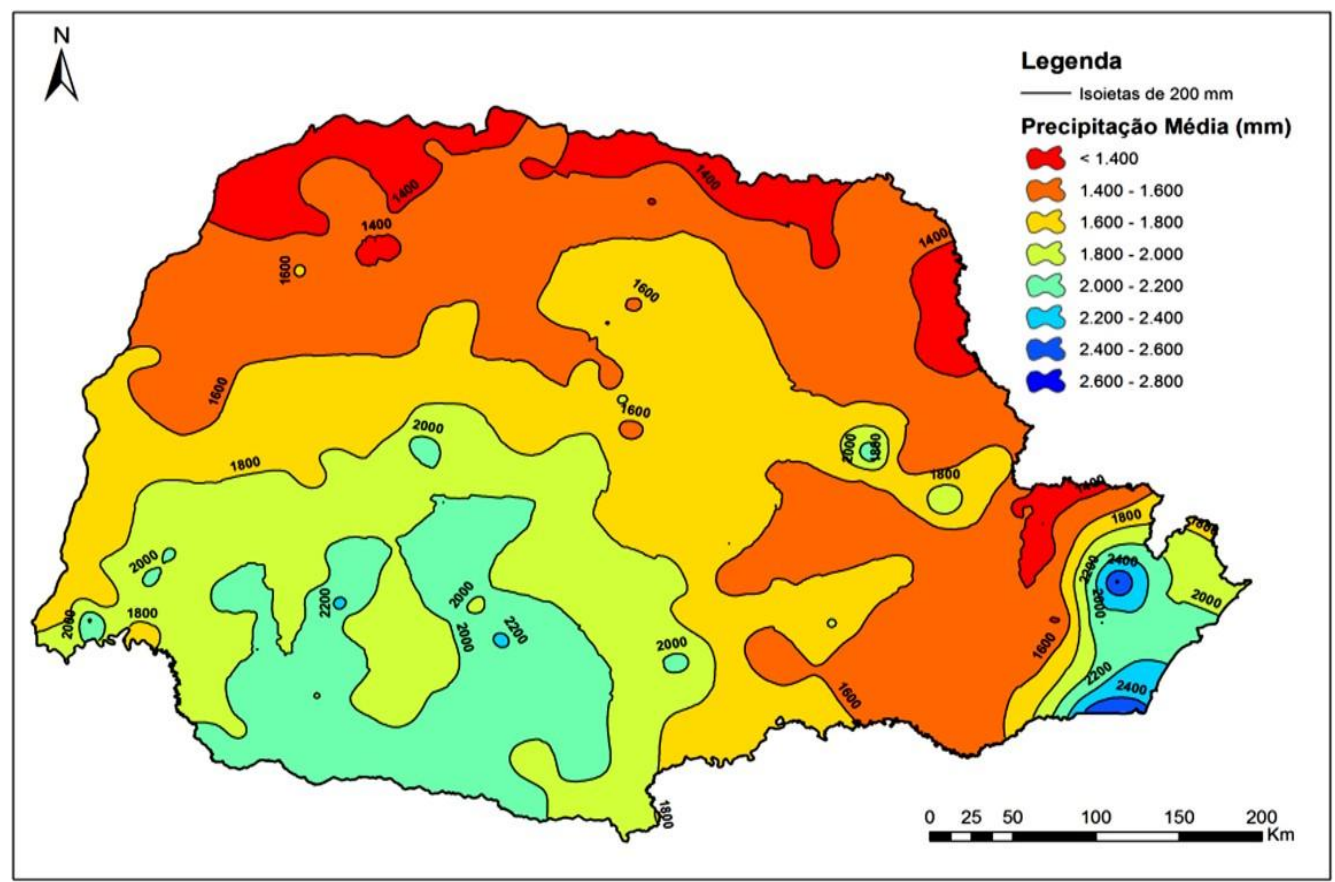

Figura 6 - Médias pluviométricas no estado do Paraná no período de 1977 a 2014.Fonte: Franco, 2017, p. 66.

Ely e Dubreuil (2017) produziram uma modelagem das tendências das precipitações anuais no Paraná e demonstraram que as tendências estatisticamente significativas são positivas para esta variável climática. Mas que as tendências à redução têm uma abrangência espacial maior, porém não significativas. As áreas que apresentaram tendências de aumento nos testes estatísticos aplicados foram as mesorregiões: metropolitana, centro-sul, oeste, centro-ocidental, norte central e norte pioneiro. $\mathrm{E}$ aquelas onde os totais anuais tendem a diminuir são: centro-oriental, norte central, noroeste, sudeste e o extremo oeste da mesorregião oeste.

No presente artigo foi aplicada a mesma metodologia empregada por Ely e Dubreuil (2017), mas para a série temporal atualizada (1977 a 2016) das precipitações sazonais e mensais, oriundas das redes do IAPAR, INMET e ANA. Por meio desta série foram gerados os mapas dos totais pluviométricos para as estações de cada ano e para cada mês que, posteriormente, foram agrupados e submetidos aos testes estatísticos disponíveis no módulo "Earth Trends Modeler 
(ETM)" do IDRISIC para a identificação das tendências espaço temporais das chuvas anuais no Paraná.

De acordo com o resultado do teste da Correlação Linear (figura 7) e considerando o valor mínimo de $r$ para uma significância de 10\% (ROGERSON, 2012) verifica-se que as precipitações durante o verão (DJF), no Paraná, apresentam tendências positivas significativas numa faixa que se estende da mesorregião metropolitana em direção ao sudeste, alcançando a mesorregião noroeste.

A tendência OLS expressa a taxa de ganho ou perda sazonal ou mensal em cada ano da série analisada. Para a estação de verão esta estatística registra um aumento de 2,31 a 3,94 mm/ano, ou seja, em 39 anos as chuvas de verão registraram um aumento superior a $150 \mathrm{~mm}$ (figura 7) que, muitas vezes, podem estar precipitando de forma concentrada. Zandonadi et al (2016) identificaram tendências positivas para a precipitação anual total na região leste da bacia do Paraná, ou seja, na área de abrangência do presente estudo. Os autores afirmam que os aumentos nas chuvas nesta região foram causados principalmente pelo aumento de eventos extremos de precipitação, especialmente aqueles acima do percentil 95 (95p). Salientam ainda que, muitas vezes, os impactos das precipitações sobre o território não são causados apenas em decorrência de chuvas superiores a $60 \mathrm{~mm}$ em 24horas, mas que chuvas em dias consecutivos superiores a 10, $20 \mathrm{~mm}$ podem deflagrá-los.
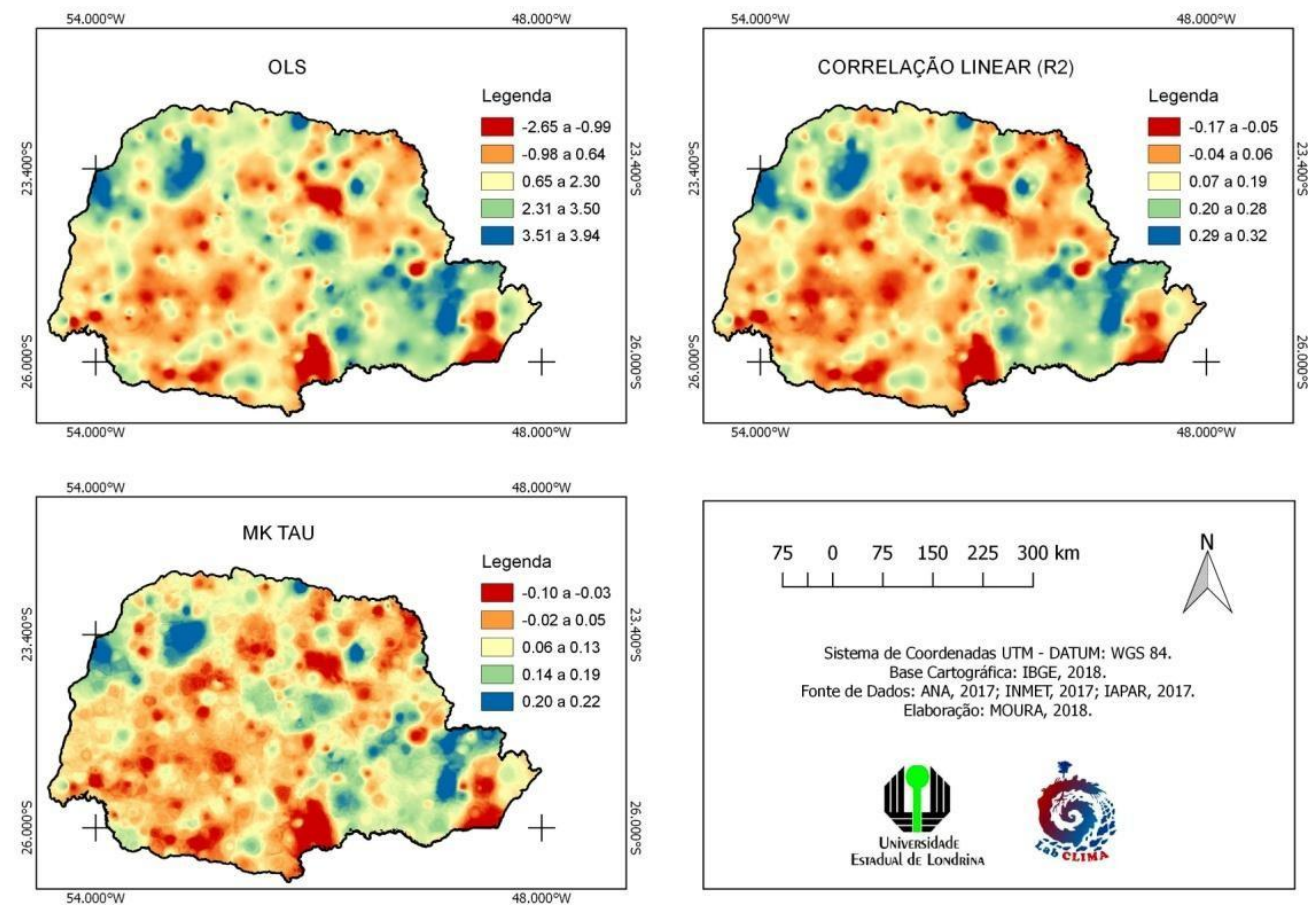

Figura 7 - Resultado dos testes estatísticos calculados para o verão no módulo "Earth Trends Modeler (ETM)" do IDRISI@). (organizado pela própria autora)

As tendências positivas e negativas calculadas por meio dos diferentes testes estatísticos para o outono não são significativas (figura 8); resultados 
similares aos encontrados por Pinheiro (2016) para a Bacia do Alto Iguaçu, localizada no sudeste do Paraná.
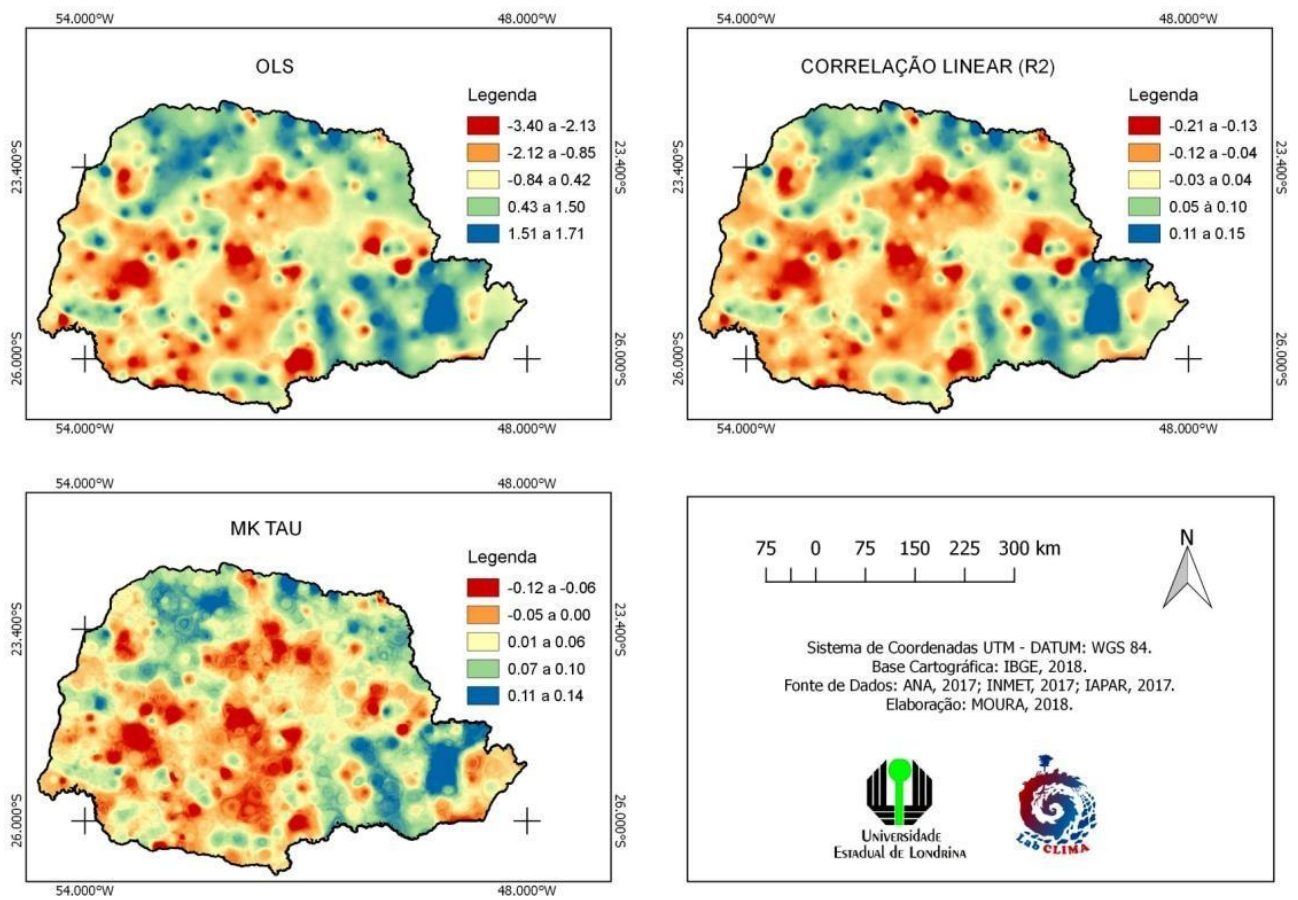

Figura 8 - Resultado dos testes estatísticos calculados para o outono no módulo "Earth Trends Modeler (ETM)" do IDRISI@). (organizado pela própria autora)

Para a estação de inverno a correlação linear apresenta tendências positivas significativas nas mesorregiões metropolitana, centro-oriental, norte pioneiro, norte central, noroeste e centro-oriental. Nestas mesorregiões o teste OLS indica um aumento de 2,71 a 4,85 $\mathrm{mm}$ para cada um dos 39 invernos espacializados (figura 9). 

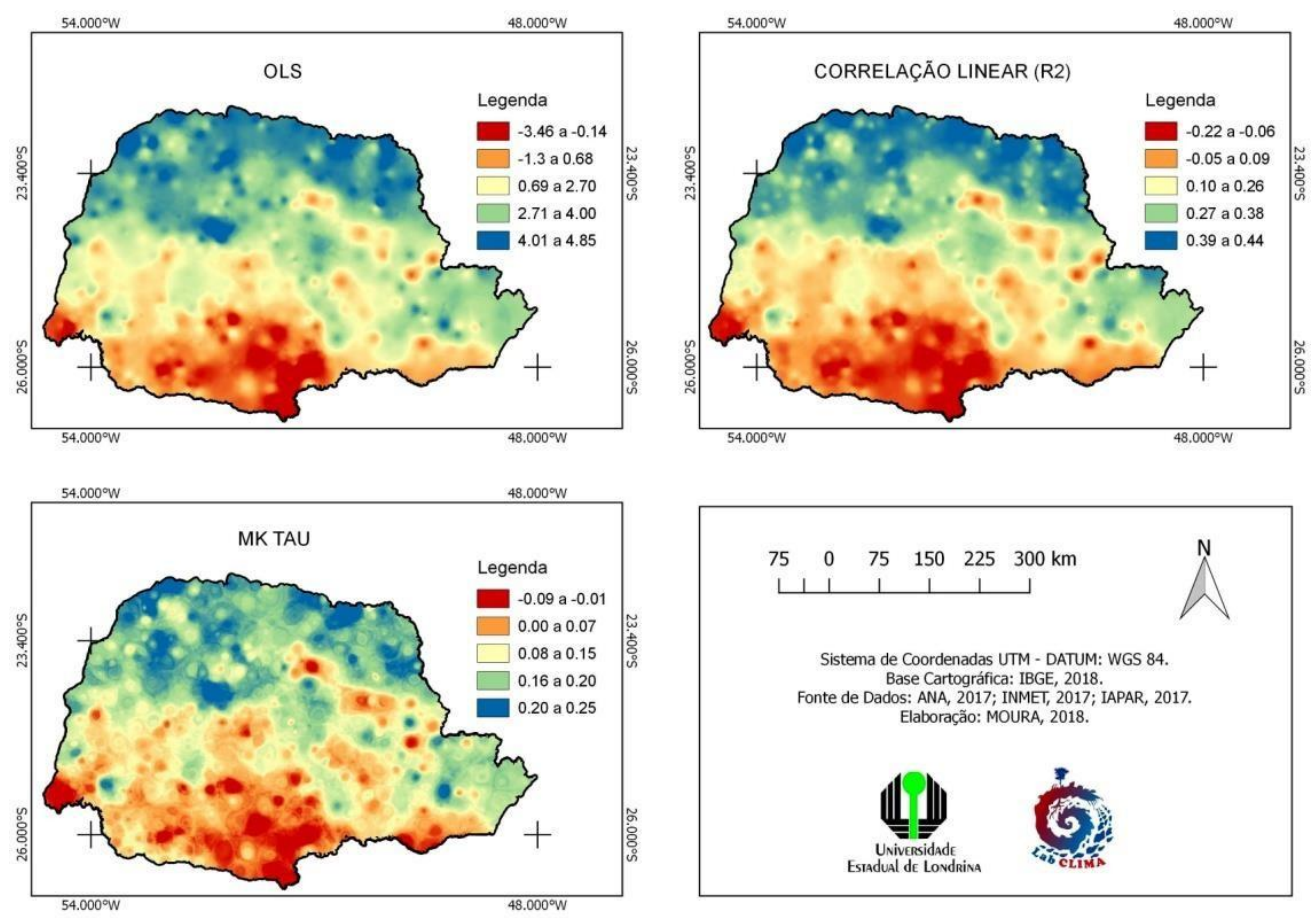

Figura 9 - Resultado dos testes estatísticos calculados para o inverno no módulo "Earth Trends Modeler (ETM)" do IDRISIC). (organizado pela própria autora)

A primavera também apresenta tendências positivas significativas para as mesorregiões metropolitana, centro-ocidental, norte pioneiro e no extremo sul da mesorregião sudeste e a tendência linear OLS indica um ganho de 3,01 a $3,2 \mathrm{~mm} / a n o$ para a série temporal analisada (figura 10). 

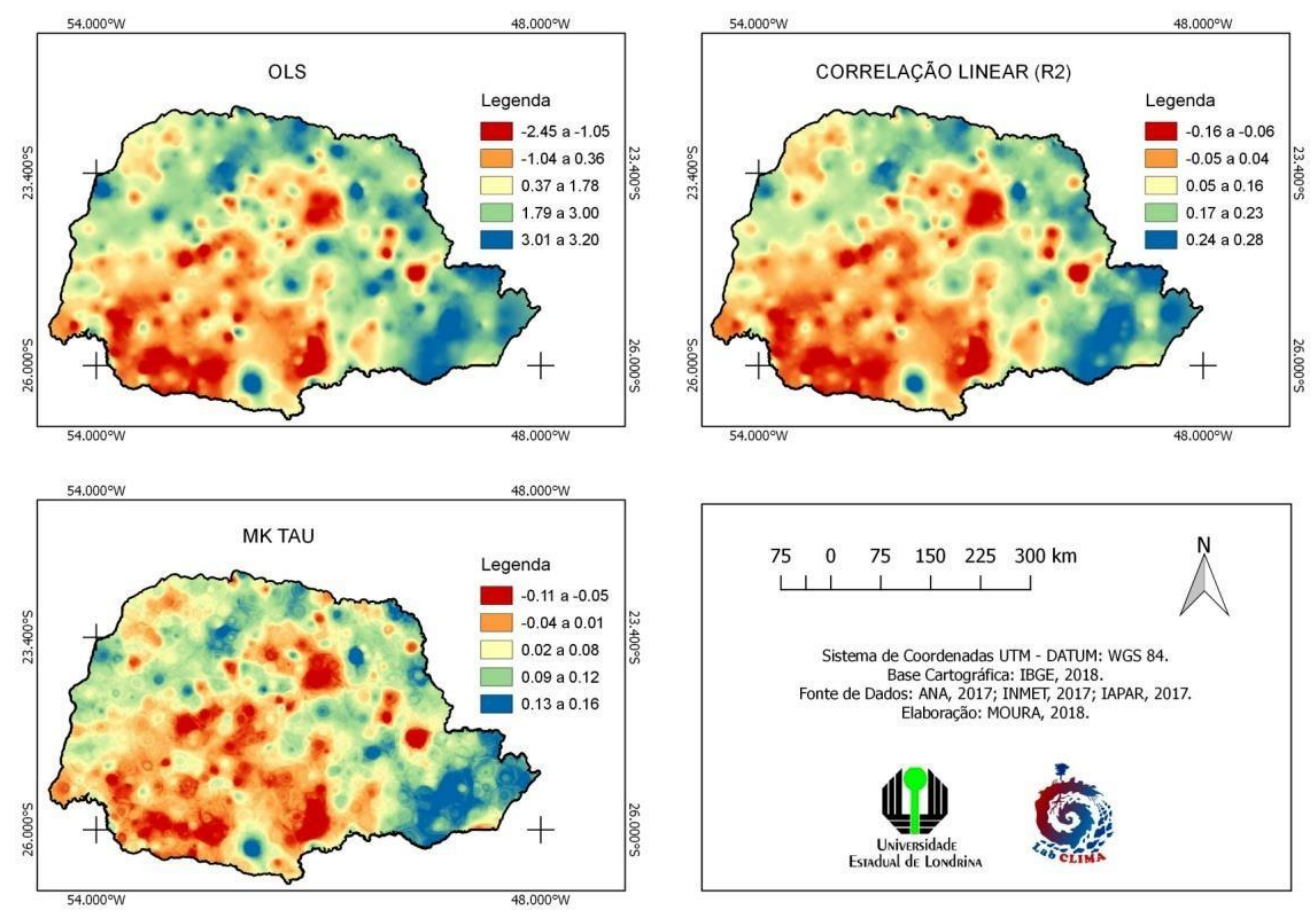

Figura 10 - Resultado dos testes estatísticos calculados para a primavera no módulo "Earth Trends Modeler (ETM)" do IDRISI@). (organizado pela própria autora)

Vale destacar que as tendências negativas calculadas por meio da Correlação linear não são estatisticamente significativas para todas as estações do ano. Penereiro et al (2018) analisaram as tendências sazonais das temperaturas e precipitações nos biomas brasileiros e identificaram que é muito mais freqüente a ausência de tendência para estas duas variáveis. Mas, salientam que a precipitação sazonal apresenta tendências positivas significativas no outono, no inverno e na primavera nos biomas da Amazônia, Cerrado e Mata Atlântica.

Também é importante salientar que os resultados obtidos por meio da tendência monotônica de Mann-Kendall contribuem para uma melhor definição das áreas com tendências positivas e negativas delineadas pela Correlação Linear para todas as estações do ano.

Os resultados do cálculo da Correlação Linear para as precipitações totais mensais estão expostos na figura 11 e não são verificadas tendências positivas e negativas significativas de acordo com o valor mínimo de $r$ calculado para uma significância de $10 \%$, ou seja, R2 superior a 0,264 de acordo com Rogerson (2012). 

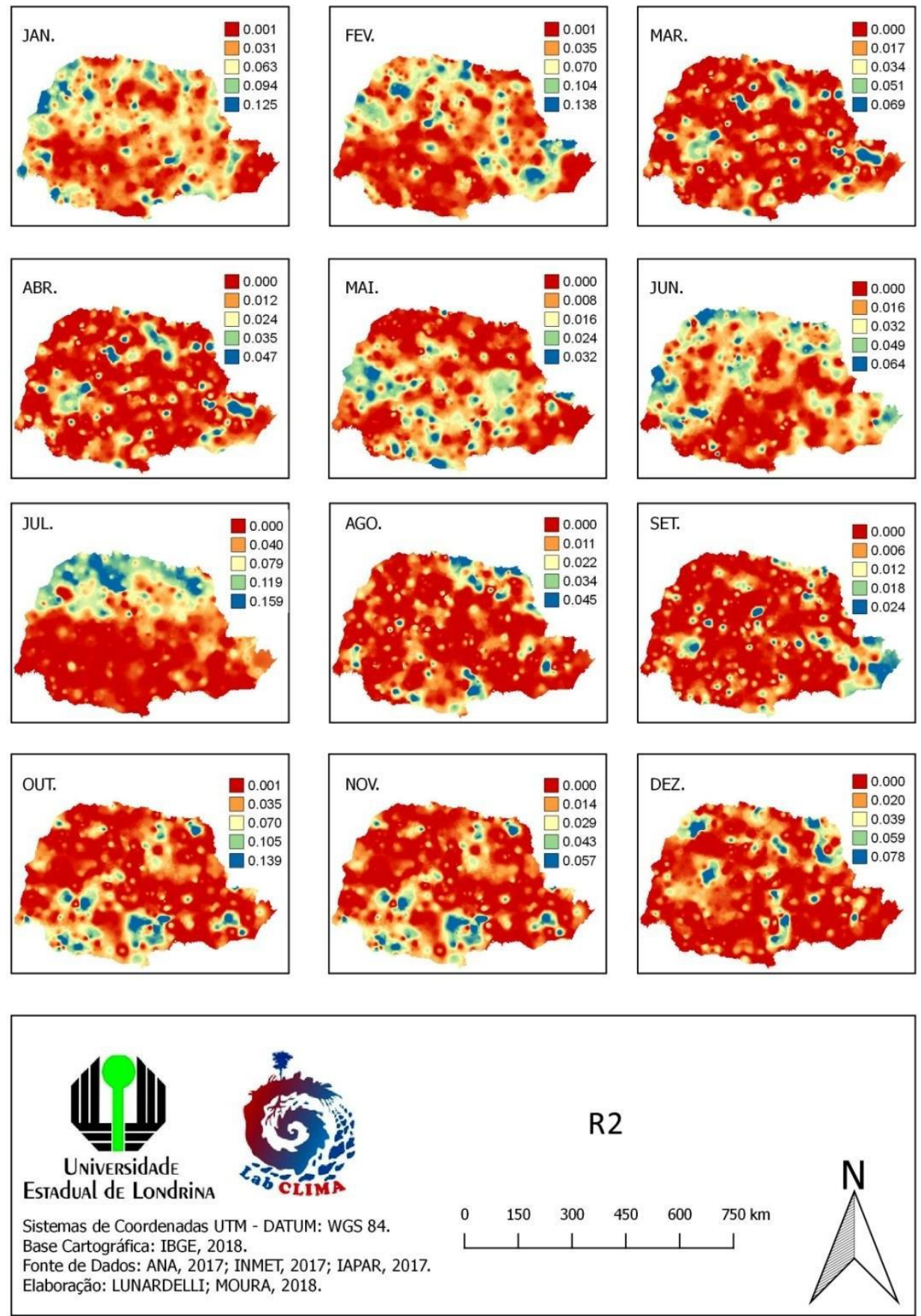

Figura 11 - Resultado do teste da Correlação Linear calculado para os totais pluviométricos mensais no estado do Paraná (1977 a 2016).(organizado pela própria autora)

Também foi elaborada a espacialização do cálculo das tendências monotônicas de Mann-Kendall (figura 12). Segundo Haylock et al (2006), o Tau 
( $\mathrm{T}$ ) de Kendall é expresso em valores que oscilam entre - 1 e 1 e tem a vantagem de propiciar a comparação de índices entre estações com quantidades de chuvas muito diferentes. Moreira e Naghettini (2016) complementam que, apesar da eficiência do teste de Mann-Kendall, ele não fornece a magnitude das tendências detectadas. Assim, no presente estudo foi constatado que a aplicação deste teste proporciona uma caracterização mais precisa das áreas com tendências positivas ou negativas delimitadas pela Correlação Linear e, considerando o mesmo valor mínimo calculado para R2 $(0,264$ para uma significância de 10\%), apenas os meses de fevereiro, julho e outubro apresentaram tendências positivas significativas. 

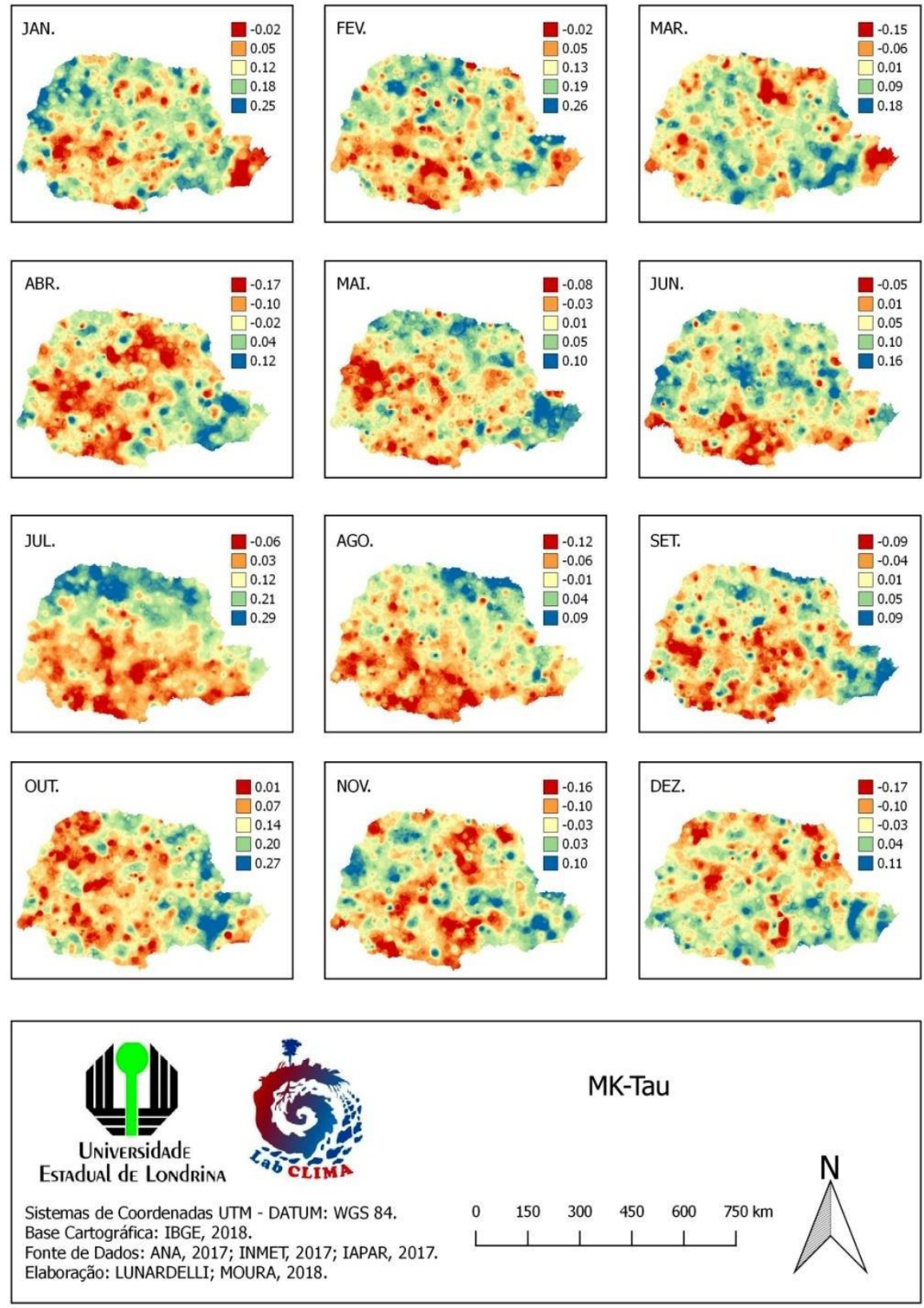

Figura 12 - Resultado do teste de Mann-Kendall tendência monotônica calculado para os totais pluviométricos mensais no estado do Paraná (1977 a 2016). (organizado pela própria autora)

A tendência linear OLS calculada para as precipitações mensais (figura 13) demonstra um aumento mais expressivo das chuvas nos meses de janeiro e junho nas mesorregiões norte central, noroeste e oeste; em fevereiro na norte central, noroeste e metropolitana; em julho em todo o norte do Paraná e na mesorregião metropolitana e em outubro nas mesorregiões metropolitana e Ano 15 - Edição Especial - XIII Simpósio Brasileiro de Climatologia Geográfica - JUN 2019 
centro-oriental. Enquanto que as tendências para a redução são identificadas para os meses de março, abril, maio, julho, novembro e dezembro; mas com índices pouco expressivos.
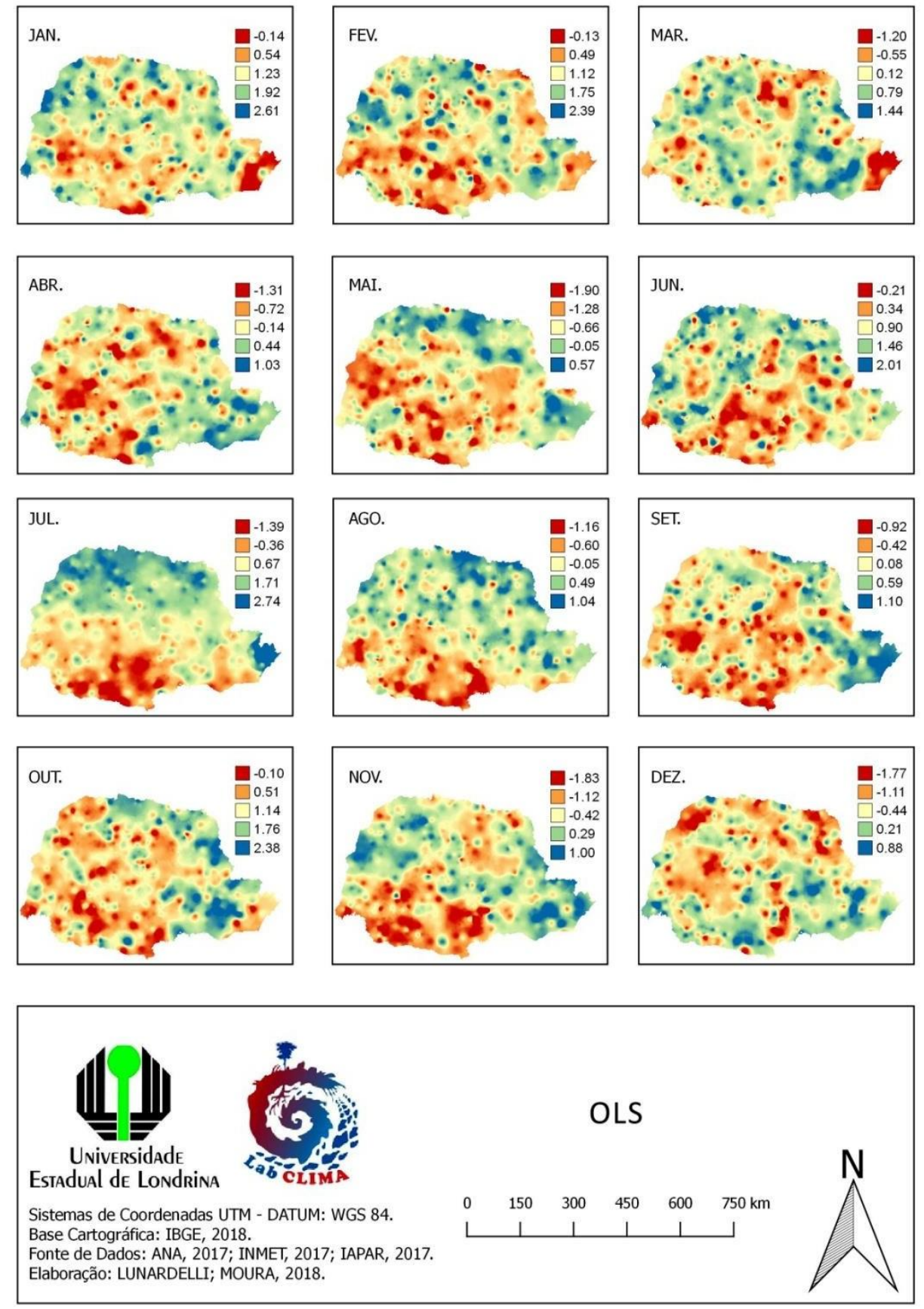

Figura 13 - Resultado da tendência OLS calculada para os totais pluviométricos mensais no estado do Paraná (1977 a 2016). (organizado pela própria autora) 
A partir dos resultados apresentados, ressalta-se que as chuvas sazonais e mensais no estado do Paraná apresentam a variabilidade característica deste fenômeno meteorológico, mas com áreas em que os valores são mais significativos para o aumento do que para a redução.

\section{CONSIDERAÇÕES FINAIS}

As análises apresentadas permitem afirmar que as chuvas anuais no Paraná, no decorrer do recorte temporal de 1977 a 2016, são organizadas em quatro períodos de acordo com a MGCTI (figura 2): 1) de 1977 a 1981 - seco; 2) entre 1982 e 1998 - úmido; 3) de 1999 a 2012 - seco e 4) úmido que parece ter iniciado no ano de 2013. Estes períodos apresentam uma estreita correlação com os índices SOI e SST; pois foi constatado que, quando este último diminui o SOI aumenta e a precipitação média anual no Paraná diminui. Porém, quando busca-se a relação contrária, esta não se concretiza.

Com relação à uma possível relação das médias pluviométricas no Paraná com as anomalias da PDO foi verificado que as médias estão em fase com este índice climático apenas nos anos de 1983, 1987 e no período de 1992 a 1999. Vale destacar que esta relação necessita ser aprofundada, por exemplo, por meio da aplicação do teste estatístico da correlação para verificar as diferentes áreas pluviométricas do estado que melhor respondem a este índice.

A metodologia aplicada às precipitações sazonais e mensais no estado do Paraná para o recorte temporal de 1977 a 2016 mostrou-se relevante para o alcance dos objetivos propostos, pois permitiu demonstrar que a tendência ao aumento das chuvas é estatisticamente significativa em diferentes áreas do estado. Mas que as tendências à redução não são significativas.

O verão apresenta tendências de aumento da precipitação numa faixa que se estende da mesorregião metropolitana em direção ao sudeste até o noroeste do estado. O inverno demonstra aumento das precipitações nas mesorregiões metropolitana, centro-oriental, norte pioneiro, norte central, noroeste e centro-oriental. Assim como a primavera registra tendência positiva nas mesorregiões metropolitana, centro-ocidental, norte pioneiro e sudeste. Enquanto que para o outono não são verificadas tendências positivas e negativas significativas.

É importante ressaltar que os resultados obtidos por meio da tendência monotônica de Mann-Kendall contribuem para uma melhor definição das áreas com tendências positivas e negativas delineadas pela Correlação Linear para todas as estações do ano.

Não foram verificadas tendências positivas e negativas estatisticamente significativas para o teste da Correlação Linear aplicado às precipitações totais mensais. Enquanto que as tendências monotônicas de Mann-Kendall propiciaram a constatação de tendências positivas significativas para os meses de fevereiro, julho e outubro.

Já a tendência linear OLS registra um aumento mais expressivo das chuvas nos meses de janeiro e junho nas mesorregiões norte central, noroeste e oeste; em fevereiro na norte central, noroeste e metropolitana; em julho em todo o norte do Paraná e na mesorregião metropolitana e em outubro nas mesorregiões metropolitana e centro-oriental. Foram verificadas tendências 
negativas para os meses de março, abril, maio, julho, novembro e dezembro; mas com índices estatisticamente não significativos.

As tendências positivas identificadas para as estações de verão, inverno e primavera são influenciadas pelos valores também positivos dos meses de janeiro, fevereiro, junho, julho e outubro que demandam por análises mais detalhadas sobre a freqüência do número de dias com chuvas, a densidade e a intensidade das precipitações.

Com o desenvolvimento deste trabalho foram constatadas tendências mais significativas para aumento nos totais pluviométricos sazonais e mensais e as mesorregiões metropolitana, norte central e noroeste com sendo as mais vulneráveis, pois apresentaram tendências positivas significativas com maior freqüência. Aspecto que merece atenção dos órgãos de planejamento e da defesa civil, pois áreas que são normalmente úmidas apresentam um aporte em suas precipitações sazonais e mensais que poderão desencadear diversos impactos sobre a estabilidade de encostas, bacias hidrográficas e, mais especificamente, sobre as áreas urbanas. Enquanto que as áreas mapeadas com tendências à redução, mesmo não sendo significativas estatisticamente, merecem uma análise mais detalhada para a identificação de períodos mais específicos em que se manifestam tais reduções; pois podem afetar sobremaneira a economia do estado, dependente das atividades agrícolas.

\section{REFERÊNCIAS}

ALMEIDA, C. T.; OLIVEIRA-JÚNIOR, J. F.; DELGADO, R. C.; CUBO, P.; RAMOS, M. C. Spatiotemporal rainfall and temperature trends throughout the Brazilian Legal Amazon, 1973-2013. International Journal of Climatology. Reading, jun. 2016. DOI: $10.1002 /$ joc.4831

AQUINO, F. E. Conexão climática entre modo anular do hemisfério sul com a península Antártica e o sul do Brasil. 2012. Tese (Doutorado) - Universidade Federal do Rio Grande do Sul, Porto Alegre, 2012.

BARROS, V. R.; DOYLE, M. E.; CAMILLONI, I. A. Precipitation trends in southeastern South America: relationship with ENSO phases and with low-level circulation. Theoretical and Applied Climatology. Viena, n. 93, p. 19-33, fev. 2008. DOI 10.1007/s00704-007-0329-x

BACK, J. Á. Aplicação de análise estatística para identificação de tendências climáticas. Pesquisa Agropecuária Brasileira. Brasília, v.36, n.5, p. 717-726, mai. 2001.

CARMELLO, V.; DUBREUIL, V.; SANT'ANNA NETO, J.L. Analyse géostatistique de la distribution spatiale des précipitations sur le versant sud du bassin du fleuve Paranapanema, dans le sud du Brésil. In: Colloque de I'Association Internationale de Climatologie, n. 28, 2015, Liège. Actes [...]. Liège, 2015. p. 439-444

CAVALCANTI, I. F. A.; AMBRIZZI, T. Teleconexões e suas influências no Brasil. In: CAVALCANTI, I. F. A.; FERREIRA, N. J, DIAS; M. A. F., JUSTI; M. G. A.

Tempo e clima no Brasil. São Paulo: Ed. Oficina de Textos, 2009. p. 317-335.

CHAKRABORTY, S.; PANDEY, R. P.; CHAUBE, U. C.; MISHRA, S. K. Trend and variability analysis of rainfall series at Seonath River Basin, Chhattisgarh (India). 
International journal of Applied Sciences and Engineering Research. v. 2, Issue 4, p. 425-434, ago. 2013. DOI: 10.6088/ijaser.020400005

DEBORTOLI, N.; DUBREUIL, V.; HEINKE, C.; RODRIGUEZ FILHO, S. Tendances et ruptures des séries pluviométriques dans la région méridionale de l'Amazonie brésilienne. In: Colloque de I'Association Internationale de Climatologie, n. 25, 2012, Grenoble. Actes [...]. Grenoble, 2012. p. 201-206

DUBREUIL, V.; MEROT, P.; DELAHAYE, D.; DESNOS, P. Changement climatique dans I'Ouest. Rennes: Presses Universitaires de Rennes, 2012.

ELY, D. F.; DUBREUIL, V. Evolutions des températures et des précipitations dans le versant sud du bassin de la rivière Paranapanema, Paraná, Brésil. In: Colloque de I'Association Internationale de Climatologie, n. 27, 2014, Dijon. Actes [...]. Dijon, 2014. p. 555-560

ELY, D. F.; DUBREUIL, V. Análise das tendências espaço-temporais das precipitações anuais para o estado do Paraná - Brasil. Revista Brasileira de Climatologia. Curitiba, Ano 13, V. 21, p. 553 - 569, Jul/Dez. 2017.

ELY, D. F.; FORTIN, G. Analyse des tendances de la pluviométrie dans le nordest de I'état du Paraná, Brésil. Actes du 31e colloque de I'AIC. Nice, p. 288 - 293, juin. 2018.

FRANCO, R. M. A variabilidade anual das chuvas no estado do Paraná e sua correlação com índices climáticos. 2017. Dissertação (mestrado) - Universidade Estadual de Londrina, Londrina, 2017.

GRIMM, A. M. (2009) Variabilidade Interanual do clima no Brasil. In: In: CAVALCANTI, I. F. A.; FERREIRA, N. J, DIAS; M. A. F., JUSTI; M. G. A. Tempo e clima no Brasil. São Paulo: Ed. Oficina de Textos, 2009. p. 353 - 374

HAYLOCK, M. R.; PETERSON, T. C.; ALVES, L. M.; AMBRIZZI, T.; ANUNCIAÇÃO, Y. M. T.; BAEZ, J.; BARROS, V. R.; BERLATO, M. A.; BIDEGAIN, M.; CORONEL, G.; CORRADI, V.; GARCIA, V. J.; GRIMM, A. M.; KAROLY, D.; MARENGO, J. A.; MARINO, M. B.; MONCUNILL, D. F.; NECHET, D.; QUINTANA, J.; REBELLO, E.; RUSTICUCCI, M.; SANTOS, J. L.; TREBEJO, I.; VINCENT, L. A. Trends in total and extreme South American rainfall 1960-2000 and links with sea surface temperature. Journal of Climate. Washignton, v. 19, p. 1490-1512, abr. 2006.

LIEBMANN, B.; VERA, C. S.; CARVALHO, L. M. V.; CAMILLONI, I. A.; HOERLING, M. P.; ALLUERD, D.; BARROS, V. R.; BA'EZ, J.; BIDEGAIN, M. An observed trend in central South American precipitation. Journal of Climate. Washignton, v. 17, p. 4357-4367, nov. 2004.

MARENGO, J. A.; JONES, R.; ALVES, L. M.; VALVERDE, M. C. Future change of temperature and precipitation extremes in South America as derived from the PRECIS regional climate modeling system. International Journal of Climatology. Reading, fev. 2009. DOI:10.1002/joc. 1863

MOREIRA, J. G. do V.; NAGHETTINI, M. Detecção de tendências monotônicas temporais e relação com erros dos tipos I e II: estudo de caso em séries de precipitações diárias máximas anuais do estado do Acre. Revista Brasileira de Meteorologia. São José dos Campos, v. 31, n. 4, p. 394-402, set. 2016. DOI: http://dx.doi.org/10.1590/0102-778631231420140155 (2016) 
NASCIMENTO JUNIOR, L. As chuvas no Paraná: Variabilidade, teleconexões, e impactos de eventos extremos. 2013. Dissertação (Mestrado) - Universidade Estadual Paulista, Presidente Prudente, 2013.

NASCIMENTO JUNIOR, L.; RODRIGUES, M. S.; DUBREUIL, V.; SANTA'ANNA NETO, J. L. Rupturas e tendências em séries históricas no Paraná. In: Simposio Brasileiro de Geografia Física Aplicada, n.15, 2013, Vitória. Anais [...], Vitória, 2013. p. 298-307

NOUACEUR, Z.; LAIGNEL, B.; TURKI, I. Changement climatique en Afrique du nord: vers des conditions plus chaudes et plus humides dans le moyen Atlas marocain et ses marges. In: Colloque de I'Association Internationale de Climatologie, n.27, 2014, Dijon. Actes [...]. Dijon, 2014. p. 387 - 393

OLIVEIRA, P. T.; SILVA, C. S.; LIMA, K. C. Climatology and trend analysis of extreme precipitation in subregions of Northeast Brazil. Theoretical and Applied Climatology. Viena, jul. 2016. DOI 10.1007/s00704-016-1865-z

OTTO, F. E.; HAUSTEIN, K.; UHE, P.; COELHO, C. A.; ARAVEQUiA, J. A.; ALMEIDA, W., et al. Factors other than climate change, main drivers of 2014/15 water shortage in southeast Brazil. Bulletin of the American Meteorological Society. Boulder, v. 96, n. 12, p. 35-40, dez. 2015.

PENEREIRO, J. C.; BADINGER, A.; MACCHERI, N. A.; MESCHIATTI, M. C. Distribuições de Tendências Sazonais de Temperatura Média e Precipitação nos Biomas Brasileiros. Revista Brasileira de Meteorologia. São José dos Campos, v. 33, n. 1, p. 97-113, jul. 2018. DOI: http://dx.doi.org/10.1590/01027786331012

PINHEIRO, G.M. Variabilidade temporo-espacial da pluviosidade na bacia do Alto Iguaçu. 2016. Tese (Doutorado) - Universidade Federal do Paraná, Curitiba, 2016.

ROGERSON, P. A. Métodos estatísticos para geografia: um guia para o estudante. Porto Alegre: Bookman, 2012.

SALVIANO, M. F.; GROPPO, J. D.; PELEGRINO, G. Q. Análise de tendências em dados de precipitação e temperatura no Brasil. Revista Brasileira de Meteorologia. São José dos Campos, v. 31, n. 1, p. 64-73, jun. 2016. DOI: http://dx.doi.org/10.1590/0102-778620150003

SILVA, I. R. Variabilidade sazonal e interanuais das precipitações na região Sul do Brasil associadas às temperaturas dos oceanos Atlântico e Pacífico. 2001. Dissertação (Mestrado) - Instituto Nacional de Pesquisas Espaciais, São José dos Campos, 2001.

SOUSA, P. Estudo da variabilidade da precipitação no estado do Paraná associado à anomalia da TSM no oceano Pacífico. 2006. Dissertação (Mestrado) - Universidade estadual de Maringá, Maringá, 2006.

TOZATO, H.; DUBREUIL, V.; DE MELLO-THÉRY, N.A. Tendências e rupturas climato-hidrológicas no sitio ramsar PARNA Pantanal (MT, Brasil). Revista Brasileira de Climatologia. Curitiba, Ano 9, v. 13, p. 164-184, jul/dez. 2014.

TRENBERTH, K. E.; FASULLO, J. T.; SHEPHERD, T. G. Attribution of climate extreme events. Nature Climate Change. Reading, Ano 5, v. 8, p. 725-730, april. 2015. DOI: http://dx.doi.org/10.1038/nclimate2657 
XAVIER, T. Ma. B. S.; XAVIER, A. F. S.; ALVES, J. M. B. Quantis e Eventos Extremos: Aplicações em Ciências da Terra e Ambientais. $1^{a}$ Ed, Fortaleza : RDS Editora / Livrarias Livro Técnico \& Distribuidora, 2007.

ZANDONADI, L.; ACQUAOTTA, F.; FRATIANNI, S.; ZAVATTINI, J. A. Changes in precipitation extremes in Brazil (Paraná River basin). Theoretical and applied climatology. Viena, p. 741-756, jan. 2016. https://doi: 10.1007/s00704-0151391-4

\section{AGRADECIMENTOS}

Agradecemos ao auxílio financeiro concedido por meio do Edital No $001 / 2016$ Redução

do risco

de desastre

REDESASTRE/SANEPAR/CEPED/FUNESPAR. 